\title{
Prevention of blindness by screening for diabetic retinopathy: a quantitative assessment
}

\author{
Thomas E Rohan, Christopher D Frost, Nicholas J Wald
}

\begin{abstract}
Diabetic retinopathy is an important cause of blindness in the Western World. A review of the randomised trials of laser photocoagulation of the retina as a method of preventing blindness from this disorder showed that this treatment is very effective, reducing the risk of blindness by $61 \%$ in a treated eye. As only one eye is needed for sight the reduction in blindness in a population will be greater than $61 \%$ because the effect of treatment in one eye is not always identical with the effect in the other eye. For analysis this reduction was taken as $73 \%$, representing the average of the minimum and maximum estimates $(61 \%$ and $85 \%)$. The effectiveness of this treatment suggests that there is the potential for a national screening programme to bring about a major reduction in blindness from this cause. A quantitative assessment of the effect of screening indicated that a programme in which patients with diabetes mellitus are systematically referred to ophthalmic opticians for a retinal examination could detect $88 \%$ of all diabetics with serious retinopathy and that $87 \%$ of these cases would be treatable. Screening and early treatment of retinopathy would prevent deterioration of visual acuity and could reduce the risk of blindness due to diabetic retinopathy by an estimated $56 \%(0.73 \times$ $0.88 \times 0.87$ ).
\end{abstract}

The findings suggest that an effectively managed community based screening programme encompassing detection, referral, treatment, and follow up would prevent about 260 new cases of blindness in diabetics under the age of 70 each year in England and Wales. This would represent over $10 \%$ of all cases of blindness in adults in this age group.

\section{Introduction}

Diabetic retinopathy is an important public health problem. It is the main cause of blindness in diabetics ${ }^{1}$ and the most important cause of blindness during adult working life. ${ }^{2}$ At present we cannot prevent the inception of diabetic retinopathy. Early detection of this disorder by screening, however, followed by appropriate intervention may offer a practical means of preventing the resulting blindness.

There are several criteria which need to be satisfied if a screening programme is to prove worth while. ${ }^{3}$ The disorder for which screening is to be conducted should be well defined, and estimates of its prevalence and rate of progression should be available; there should be an effective treatment; the screening test should be simple and safe and capable of discriminating adequately between affected and unaffected people; those with a positive test result should have a sufficiently high chance of being affected; the facilities for a screening programme should be available or easily installed; and the programme should be cost effective.

We review the evidence on screening for diabetic retinopathy in the light of these criteria and provide a quantitative assessment of the implications of mounting a screening programme for diabetic retinopathy in England and Wales, in terms of the number of people to be screened and the number of cases of blindness which might be prevented.

\section{Prevalence, incidence, and natural course of diabetic retinopathy}

Diabetic retinopathy is a manifestation of diabetic microangiopathy. ${ }^{4}$ It is thought to evolve through several stages (fig 1), background (early) retinopathy generally progressing either to maculopathy or to proliferative retinopathy. Proliferative retinopathy is more characteristic of early onset diabetes, whereas maculopathy is more characteristic of late onset diabetes. Both types of retinopathy can lead to blindness. Hereafter we refer to these two types of retinopathy as serious diabetic retinopathy.

The prevalence of diabetic retinopathy has been measured in several population based studies. ${ }^{5.8}$ The findings suggest that the prevalence of the more severe grades ranges from about $3 \% \%^{58}$ to $10 \%{ }^{67}$ of diabetics.

Dwyer $e t$ al estimated the incidence of proliferative retinopathy among diabetics to be $1 \cdot 6 / 1000$ person years ${ }^{8}$ The incidence of maculopathy can be estimated by using data from the study of Burns-Cox and Hart. ${ }^{9}$ They found that maculopathy was 2.6 times as common as proliferative retinopathy, which suggests that the incidence of maculopathy is about $4 \cdot 2 / 1000$ person years $(4.2=2.6 \times 1.6)$. An estimate of the incidence of serious diabetic retinopathy is therefore $5 \cdot 8 / 1000$ person years $(5 \cdot 8=1 \cdot 6+4 \cdot 2)$. Sorsby presented age specific incidence rates of blindness due to diabetic retinopathy in England and Wales. ${ }^{10} \mathrm{By}$ applying these rates to the underlying population ${ }^{11}$ it can be calculated that roughly 460 new cases of blindness due to diabetic retinopathy may be expected to occur each year in people aged under 70 (table I).

There is little information on the average duration of each stage of the natural course of diabetic retinopathy. Dwyer et al, however, reported that 20 years after the initial diagnosis of diabetes the cumulative incidence of retinopathy was $34.5 \%$, whereas the cumulative incidence of proliferative retinopathy was $5 \% .{ }^{8}$ This suggests a fairly slow progression to the more severe forms of retinopathy in most cases and raises the possibility of detection of retinopathy at an early stage followed by appropriate intervention.

\section{Treatment}

There is good evidence that treatment of diabetic retinopathy by argon laser or xenon arc photocoagulation of the retinal tissue is effective. Several randomised controlled trials in which the eyes of patients were randomised either to receive or not to receive photocoagulation have been performed. ${ }^{12-18}$ Measures of outcome were either blindness or deterioration in visual acuity as measured by a decrease of two lines or more in the number of lines of a visual acuity chart which could be read. Table II presents the results from those studies which used blindness - defined as a visual acuity of $<6 / 60$-as a measure of outcome. ${ }^{12-16}$ The studies were all of the matched prospective type, and two measures of relative risk are important. The first, 
the matched odds ratio, is the ratio of the number of patients who suffered blindness in the treated eye but not the untreated eye to the number who suffered blindness in the untreated eye but not the treated eye. Information on people who suffered blindness in both

TABLE I-Expected annual incidence of blindness due to diabetic retinopathy in England and Wales

\begin{tabular}{|c|c|c|c|c|c|c|}
\hline & & \multicolumn{4}{|c|}{ Age (years) } & \multirow[b]{2}{*}{ Total } \\
\hline & & $15-49$ & $50-59$ & $60-64$ & $465-69$ & \\
\hline \multirow{3}{*}{ Males } & Incidence $/ 10^{\circ} /$ year & 4.7 & $14 \cdot 8$ & $35 \cdot 7$ & $35 \cdot 7 \dagger$ & \\
\hline & $\left\{\begin{array}{l}\text { No of males in England and } \\
\text { Wales }\left(\times 10^{\circ}\right) \ddagger\end{array}\right.$ & $12 \cdot 5$ & $2 \cdot 7$ & & & \\
\hline & $\begin{array}{l}\text { Expected No of cases of } \\
\text { blindness each year }\end{array}$ & 59 & 40 & & 39 & 184 \\
\hline \multirow{3}{*}{ Females } & Incidence $/ 10^{\star} /$ year $^{\star}$ & $2 \cdot 6$ & $25 \cdot 2$ & $65 \cdot 0$ & $65 \cdot 0 \dagger$ & \\
\hline & $\left\{\begin{array}{l}\text { No of females in England and } \\
\text { Wales }\left(\times 10^{\circ}\right) \ddagger\end{array}\right.$ & $12 \cdot 3$ & $2 \cdot 7$ & $1 \cdot 4$ & 1.3 & \\
\hline & $\begin{array}{l}\text { Expected No of cases of } \\
\text { blindness each year }\end{array}$ & 32 & & 91 & 85 & 276 \\
\hline
\end{tabular}

^Incidences are weighted averages of annual incidences of blindness due to diabetic retinopathy in England and Wales from 1963 to 1968, calculated by using corresponding background populations as weights; rates obtained using correspo

from Sorsby."

tIncidence among 65-69 year olds assumed to be same as that among 60-64 year olds.

$\ddagger$ Estimated resident population as at 30 June 1986 ."

TABLE II - Prevention of blindness due to diabetic retinopathy by photocoagulation: summary of randomised controlled trials

\begin{tabular}{|c|c|c|c|c|c|c|}
\hline Reference & $\begin{array}{l}\text { No of } \\
\text { patients } \\
\text { enrolled }\end{array}$ & $\begin{array}{l}\text { Duration of } \\
\text { follow up } \\
\text { (years) }\end{array}$ & $\begin{array}{l}\text { Condition } \\
\text { treated }\end{array}$ & $\begin{array}{c}\text { Method of } \\
\text { photocoagulation }\end{array}$ & $\begin{array}{c}\text { No blind } \\
\text { in treated } \\
\text { eye/No } \\
\text { blind in } \\
\text { untreated } \\
\text { eye }\end{array}$ & $\begin{array}{c}\text { Relative risk }{ }^{\star} \\
\text { (95\% confidence } \\
\text { interval })\end{array}$ \\
\hline Hercules $e t a l^{12}$ & 94 & 3 & $\begin{array}{l}\text { Proliferative } \\
\text { retinopathy }\end{array}$ & Argon laser & $7 / 36$ & $0 \cdot 19(0 \cdot 10$ to 0.39$) \ddagger$ \\
\hline $\begin{array}{l}\text { British Multicentre Study } \\
\text { Group }\end{array}$ & 107 & 5 & $\begin{array}{l}\text { Proliferative } \\
\text { retinopathy }\end{array}$ & Xenon arc & $10 / 34$ & $0.29(0.16$ to 0.54$) \neq$ \\
\hline $\begin{array}{l}\text { Diabetic Retinopathy } \\
\text { Study Research Group }{ }^{14}\end{array}$ & 1758 & $1^{1 / 2 \dagger}$ & $\begin{array}{l}\text { Proliferative } \\
\text { retinopathy }\end{array}$ & $\begin{array}{l}\text { Argon laser and } \\
\text { xenon arc }\end{array}$ & $66 / 157 \dagger$ & $0.42(0.32$ to 0.56$) \S$ \\
\hline $\begin{array}{l}\text { British Multicentre Study } \\
\text { Group's }\end{array}$ & 99 & 5 & Maculopathy & Xenon arc & $19 / 39$ & $0.49(0.32$ to 0.73$) \ddagger$ \\
\hline Stenkula $^{16}$ & 185 & 4 & $\begin{array}{l}\text { Proliferative } \\
\text { retinopathy } \\
\text { and } \\
\text { maculopathy }\end{array}$ & $\begin{array}{l}\text { Argon laser and } \\
\text { xenon arc } \\
y\end{array}$ & $18 / 27$ & $0.67(0.37$ to 1.21$) \oint$ \\
\hline
\end{tabular}

All studies combined

2243

$0 \cdot 39(0 \cdot 28$ to $0 \cdot 55)$

*Risk of blindness in treated eye relative to risk of unity in untreated eye.

†Estimated from table II and figure 4 in reference with assumption of uniform recruitment over recruitment period of study.

$\ddagger$ Confidence interval for matched prospective study $\left(\operatorname{Rothman}^{10}\right)$.

SConfidence interval for unmatched prospective study $\left(\right.$ Rothman $\left.^{19}\right)$; matched results not quoted in papers.

"Combined by method of DerSimonian and Laird."

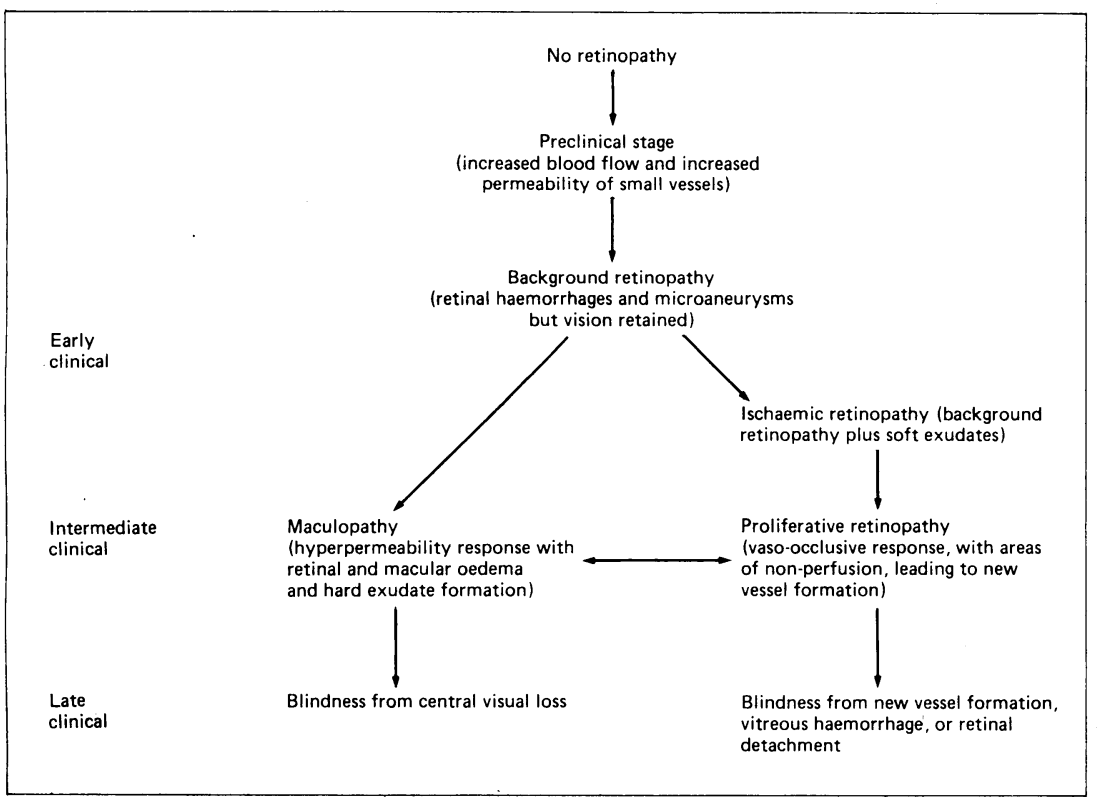

FIG 1-Natural course of diabetic retinopathy (Foulds et al ${ }^{1}$ and Kohner ${ }^{+}$) eyes or in neither eye is ignored as uninformative. The matched odds ratio provides the most powerful test of the efficacy of the treatment.

The second measure is the unmatched relative risk, which is the risk of blindness in a treated eye divided by the risk in an untreated eye. This is a less powerful test of the efficacy of treatment but is the correct estimate of the effect of treatment applied on a population basis. To illustrate the difference between the two measures, consider the hypothetical case in which $90 \%$ of study subjects go blind in both eyes and the other $10 \%$ go blind only in the untreated eye. The matched odds ratio is zero, indicating that for eyes in which there is the potential to alter prognosis treatment is always effective. The unmatched relative risk, however, is $9 / 10$, indicating that treatment applied on a population basis would prevent $10 \%$ of eyes going blind. As this paper is concerned with the effect of screening for the prevention of blindness in the population as a whole, table II shows estimates of the unmatched relative risks together with confidence intervals calculated by the method of Rothman. ${ }^{19}$

A combined "best estimate" of the relative risk of blindness associated with photocoagulation was calculated from the five trials in which blindness was examined as a measure of outcome. As the trials exhibited a degree of heterogeneity $\left(\chi^{2}{ }_{4}\right.$ for heterogeneity $=9.5 ; p=0.05$ ), the method of DerSimonian and Laird was used to produce a combined relative risk. ${ }^{20}$ Relative to a risk of unity in untreated eyes with retinopathy, the combined estimate of the risk of blindness in eyes treated by photocoagulation was $0.39(95 \%$ confidence interval 0.28 to 0.55$)$. Thus photocoagulation reduced the risk of blindness in ? treated eye by $61 \%$.

As only one eye is needed for sight the reduction in blindness in a population will be greater than $61 \%$ because the effect of treatment in one eye is not ait: identical with the effect in the other eye. If the effect on treatment in one eye is completely unrelated to the effect in the other, then the $61 \%$ reduction in blindness per eye is equivalent to an $85 \%$ reduction in blindness per person, as the probability of going blind in both treated eyes is $0.39 \times 0 \cdot 39$, or $0 \cdot 15$. The true population estimate is likely to lie between these values and so in our subsequent calculations we have assumed that the reduction in blindness will be $73 \%$, the average of the maximum and minimum estimates. This figure is arbitrary but reasonable and allows us to estimate the effect of screening in practice. Alternative figures can be adopted and easily applied.

\section{Screening}

The long term impact on visual acuity of a screening programme for the detection of serious diabetic retinopathy does not seem to have been evaluated. Nevertheless, in several reports the ability of ophthalmic opticians ${ }^{921}$ and of ophthalmologists and diabetologists ${ }^{1}$ to detect diabetic retinopathy has been examined. Burns-Cox and Hart reported results from a programme in which opticians screened diabetics for retinopathy. ${ }^{9}$ In that programme, conducted in the Frenchay health district, diabetics in hospital wards or attending diabetic clinics, general practitioners, or ophthalmic opticians were invited to visit opticians for annual eye checks. For each diabetic patient screened the corrected visual acuity and the retinal findings were recorded by an optician and forwarded to the investigators. In general, screened subjects whose retinas were normal or showed minimal background changes were not referred to ophthalmologists for further assessment (screen negative subjects), whereas those with more advanced retinopathy (that is, with new vessels anywhere on the retina or exudates near the 
TABLE III-Numbers of people calculated to have true and false positive and true and false negative results in study of Burns-Cox and Hart $^{9}$

\begin{tabular}{lccc}
\hline & \multicolumn{3}{c}{$\begin{array}{c}\text { Definitive test result } \\
\text { (ophthalmologist's diagnosis) }\end{array}$} \\
\cline { 2 - 4 } $\begin{array}{l}\text { Screening test result } \\
\text { (optician's diagnosis) }\end{array}$ & Positive & Negative & Total \\
\hline $\begin{array}{lccc}\text { Positive } \\
\text { Negative }\end{array}$ & $2^{\star \star}$ & 43 & 72 \\
\hline Total & 33 & 781 & 814 \\
\hline
\end{tabular}

\section{Screening results}

Prevalence of serious diabetic retinopathy

Detection rate

False positive rate

$4 \cdot 1 \%(33 / 814)$ $5 \cdot 5 \%(43 / 781)$

^Follow up of both positive and negative screenees incomplete. Proportion of true positives among those lost to follow up assumed to be the same as among those followed up.

macula) or with an appreciable change in visual acuity in the absence of other pathological changes were referred (screen positive subjects). A sample of screen negative subjects was also invited for further assessment.

Table III summarises the results of the study by Burns-Cox and Hart.' The footnote to table III describes the method used to allow for losses to follow up, which is similar to that described by Bhopal and Hedley. ${ }^{22}$ Table III shows that the detection rate of the screening test was $88 \%(29 / 33$ patients) and its false positive rate $5 \cdot 5 \%(43 / 781)$. Other studies of screening for diabetic retinopathy were reported by $\mathrm{Hill}^{21}$ and by Foulds et $a l,{ }^{1}$ Hill presenting results in an abstract (detection rate $79 \%$; false positive rate $21 \%$ ) and Foulds et al specifying only a positive predictive value of $76 \%$. Of the three studies, that of Burns-Cox and Hart was the most fully documented and probably the most applicable to future screening practice-given that it was optician based, and opticians are more readily accessible to the general public than physicians or ophthalmologists. In assessing the probable impact of screening for diabetic retinopathy we have therefore adopted the detection and false positive rates from that study.

Screening for diabetic retinopathy in England and Wales: a quantitative assessment

Before a screening programme for diabetic retinopathy is mounted in England and Wales consideration needs to be given to the implications that it would have in terms of the number of people to be screened, the number of cases of blindness which might be prevented, and the frequency of screening.

From the figures calculated above, together with an estimate from Burns-Cox and Hart ${ }^{9}$ of the proportion of screen detected patients who are treatable we can estimate the average number of cases of blindness which could be prevented in England and Wales each year by mounting a screening programme for diabetic retinopathy among diabetics under the age of 70 . Table IV shows that each year an estimated 260 cases could be prevented. This represents over $10 \%$ of all cases of blindness in this age group. ${ }^{2}$ A screening programme for diabetic retinopathy would also lead to the detection of other potentially sight threatening

TABLE IV-Cases of blindness due to diabetic retinopathy in England and Wales

Number of persons per year

Cases in patients aged under 70 (see table I)

Detectable cases ( $88 \%$; see table III)

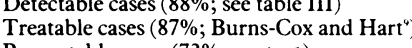

460

460

350

Preventable cases $(73 \%$; see text conditions-for example, cataract and retinal detachment - and probably, therefore, to the prevention of additional cases of blindness.

For several reasons our estimate of the benefit of screening is probably conservative. Firstly, and most importantly, a screening programme in diabetics under the age of 70 would prevent some cases of blindness in diabetics over 70 . If the average time between treatment and the onset of blindness is five years calculations along the lines of those in tables I-IV suggest that this would amount to around 70 cases of blindness among the over 70s being prevented a year. Secondly, registration of the blind is incomplete ${ }^{1023}$ so that the incidence rates shown in table I are probably underestimates of the true incidence rates. Thirdly, the assumed detection rate of $88 \%$ applies to the prevalence screening examination. The detection rate for the whole screening process might be higher because some cases missed at the prevalence screening examination might be detected at subsequent examinations when the disease was still treatable. Fourthly, in the absence of information on the incidence rate of blindness due to diabetic retinopathy in people aged 65 or more we assumed that they were the same as those in people aged 60-64. This is probably not an unreasonable assumption but may have contributed to underestimation of the benefit. We have assumed a compliance rate of $100 \%$. In practice there would be less than a $100 \%$ response to the invitation to be screened. Compliance, however, would probably be high, as diabetics would be motivated to participate in such programmes because of their knowledge about their disease.

Figure 2 shows the estimated number of people who would be involved in a screening programme in which all diabetics under the age of 70 in England and Wales were invited each year for a screening examination together with the numbers who would be expected to need treatment at the prevalence screening examination and in typical subsequent years. Figure 2 shows that in a typical year about 2000 patients would need treatment. This may seem high in view of our estimate that only 260 cases of blindness would be prevented on average each year. It is, however, not surprising for two reasons. Firstly, because data from the untreated eyes in randomised trials (table II) show that most eyes judged to need treatment do not become blind even if left untreated and, secondly, because blindness is not prevented in all treated cases. In a typical year in a typical health authority (there are about 200 health authorities in England and Wales) there would be 135 referrals of patients, 10 of whom would require treatment. Therefore, little additional load would be placed on existing hospital services.

We have not drawn a distinction between insulin dependent and non-insulin dependent diabetes. Risk of retinopathy is three times higher in insulin dependent diabetes, ${ }^{8}$ which might suggest that these patients should be screened more frequently. Nevertheless, without further information on the distribution and natural course of maculopathy and proliferative retinopathy by type of diabetes it is not possible to formulate a definitive policy on this issue. If a screening programme for diabetic retinopathy were to be implemented the question of recall policy could be evaluated formally by randomising subjects to different recall times.

\section{Conclusion}

Screening diabetic patients for diabetic retinopathy satisfies the main requirements for a worthwhile screening programme. Screening can prevent 260 people becoming blind each year and, though a formal economic assessment has not been performed (and will 


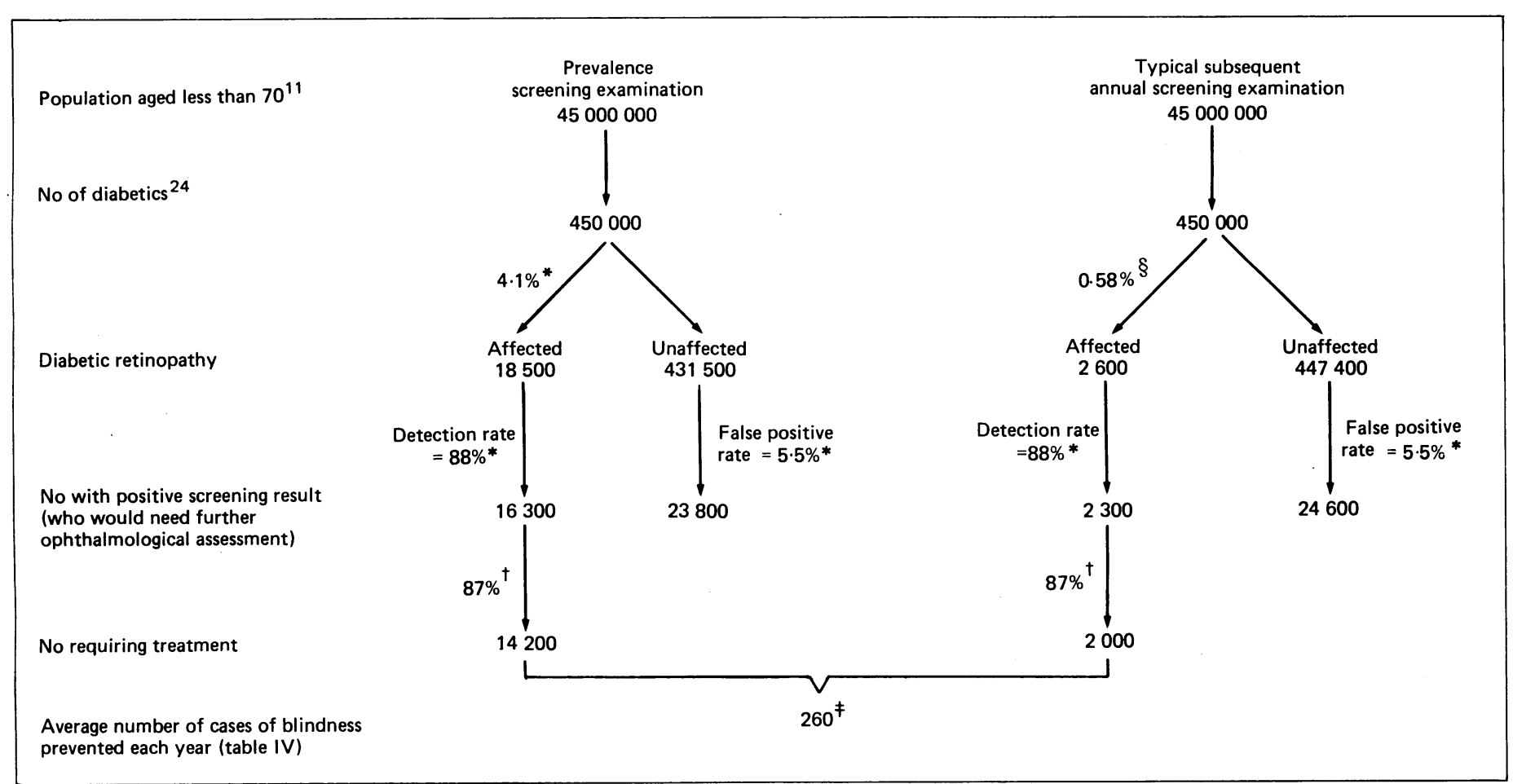

FIG 2-Numbers to be screened, referred, and treated at prevalence screening examination and at typical subsequent annual screening examination for diabetic retinopathy in England and Wales

$\star$ Obtained from table III. †Obtained from Burns-Cox and Hart. ${ }^{9} \quad$ †Obtained from table IV. \Estimated prevalence of diabetic retinopathy at an annual screening round. In a screening programme with a high detection rate the prevalence of disease at a typical screening examination after the prevalence examination will be similar to the incidence of the disease over the period between screening examinations. For an annual screening programme the prevalence is roughly equal to the annual incidence of diabetic retinopathy.

depend greatly on such factors as the frequency of recall), it is clear that the potential benefit to patients in terms of improved quality of life is substantial.

We thank Professor Anthony Bron, Mr Hung Cheng, Dr Cecily Kelleher, and $\mathrm{Mr}$ Nicholas Wells for their helpful comments on the manuscript.

1 Foulds WS, McCuish A, Barrie T, et al. Diabetic retinopathy in the west of Scotland: its detection and prevalence, and the cost-effectiveness of a Scotland: its detection and prevalence, and the cost-effectiveness

2 Government Statistical Service. Causes of blindness and partial sight among aduls in 1976/77 and 1980/81 England. London: HMSO, 1988.

3 Cuckle HS, Wald NJ. Introduction: principles of screening. In: Wald NJ, ed. Antenatal and neonatal screening. Oxford: Oxford University Press, 1984 $1-22$

4 Kohner EM. The evolution and natural history of diabetic retinopathy. In Ophthalmol Clin 1978;18:1-16.

5 Houston A. Retinopathy in the Poole area: an epidemiological enquiry. In Eschwege R, ed. Advances in diabetes epidemiology. Amsterdam: Elsevie Biomedical Press, 1982:199-206. (INSERM symposium No 22.

6 Klein R, Klein BEK, Moss SE, David MD, De Mets DL. The Wisconsin epidemiologic study of diabetic retinopathy. II. Prevalence and risk of diaberic rinopaty when age at diagnosis is less than 30 years. Arch diabetic retinopathy when
Ophthalmol 1984;102:520-6.

7 Klein R, Klein BEK, Moss SE, David MD, De Mets DL. The Wisconsin epidemiologic study of diabetic retinopathy. III. Prevalence and risk of diabetic retinopathy when age at diagnosis is 30 or more years. Arch Ophthalmol 1984;102:527-32.

8 Dwyer MS, Melton IJ, Ballard DJ, Palumbo PJ, Trautmann JC, Chu C. Incidence of diabetic retinopathy and blindness: a population-based study in Rochester, Minnesota. Diabetes Care 1985;8:316-22.

9 Burns-Cox CJ, Hart JCD. Screening of diabetics for retinopathy by ophthalmic opticians. Br Med f 1985;290:1052-4.

10 Sorsby A. The incidence and causes of blindness in England and Wales 1963 68. Reports on Public Health and Medical Subjects 1972; No 128:20, 33

11 Office of Population Censuses and Surveys. Mortality statistics. London: HMSO, 1988:1. (Series DHQ, No 17.)

12 Hercules BL, Gayed II, Lucas SB, Jeacock J. Peripheral retinal ablation in the treatment of proliferative diabetic retinopathy: a three-year interim report of a randomised, controlled study using the argon laser. $\mathrm{Br} \mathcal{J}$ Ophthalmol a randomised, 1977 ; 1 :555-63.

13 British Multicentre Study Group. Photocoagulation for proliferative diabetic retinopathy: a randomised controlled clinical trial using the xenon-arc. Diabetologia 1984;26:109-15.

14 Diabetic Retinopathy Study Research Group. Photocoagulation treatment of proliferative diabetic retinopathy. Ophthalmology 1981;88:583-600. (Repor No 8.)

15 British Multicentre Study Group. Photocoagulation for diabetic maculopathy A randomised controlled clinical trial using the xenon-arc. Diabetes 1983;32 1010-6.

16 Stenkula S. Photocoagulation in diabetic retinopathy. A multicentre study in Sweden. Acta Ophthalmol 1984;suppl 162:1-100.

17 Patz A, Schatz H, Berkow JW, Gittelsohn AM, Ticho U. Macular edema - an overlooked complication of diabetic retinopathy. Transactions of the American Academy of Ophthalmology and Otology 1973;77:34-42.
18 Blankenship GW. Diabetic macular edema and argon lazer photocoagulation: a prospective randomised study. Ophthalmology 1979;86:69-75.

19 Rothman KJ. Modern epidemiology. Boston: Little Brown, 1986. 20 DerSimonian R, Laird N. Meta-analysis in clinical trials. Controlled Clin Trials

21 Hill RD. Screening for diabetic retinopathy at primary care level. Diabetologia 1981;20:9.

22 Bhopal RS, Hedley AJ. Screening of diabetics for retinopathy by ophthalmic opticians. Br Med f 1985;290:1589.

23 British Diabetic Association Committee on Blindness. A report on diabetic blindness in the United Kingdom. London: British Diabetic Association, 1969.

24 Hamman RF. Diabetes in affluent societies. In: Mann JI, Pyorala K, Teuscher A, eds. Diabetes in epidemiological perspective. Edinburgh: Churchill Livingstone, 1983:7-42.

(Accepted 4 September 1989)

\section{ONE HUNDRED YEARS AGO}

The Bill introduced by Sir Henry Roscoe to amend the Dogs Act of 1871 proposes to put in force a series of stringent regulations on the subject. The owner of any dog (not specially exempted) that is "permitted or suffered to be at large" in any part of the United Kingdom without wearing a muzzle "of a form to be approved by the Privy Council," shall be liable to a penalty of twenty shillings. The owner shall also be liable for all "injury done to the person" by the dog, without any proof being required of "previous mischievous propensity" on the part of the dog, or of negligence on the part of the owner. Every dog must wear a metal ticket with date and number of licence, the penalty being as before the seizure of the animal and fining of the owner. Every dog lost shall be reported to the police within three days under pain of a penalty. Any "appearance or symptom" of rabies shall be immediately reported to the police. Every dog seized by the police shall be examined by a veterinary surgeon, and, if condemned, "disposed of under the provisions of the Act," and "the carcase shall be burned." (British Medical Fournal 1889;ii:28) 